\section{rief}

OPEN ACCESS

Citation: P. Huion, H. Sayer, R. Pinto-Bello Gomez. (2021) From Radicals to Community Builders: Reframing the Roles of Women through Design Thinking. Rief 18, 2: pp. 27-39. doi: https://doi. org/10.36253/rief-10520.

Copyright: (c) 2021 P. Huion, H. Sayer, R. Pinto-Bello Gomez. This is an open access, peer-reviewed article published by Firenze University Press (https:// oaj.fupress.net/index.php/rief) and distributed under the terms of the Creative Commons Attribution License, which permits unrestricted use, distribution, and reproduction in any medium, provided the original author and source are credited.

Data Availability Statement: All relevant data are within the paper and its Supporting Information files.

Competing Interests: The Author(s) declare(s) no conflict of interest.
Firenze University Press

https://oaj.fupress.net/index.php/rief

\title{
From Radicals to Community Builders: Reframing the Roles of Women through Design Thinking
}

\author{
Patricia Huion ${ }^{1}$, Handan Sayer ${ }^{2}$, \\ Raquel Pinto-Bello Gomez ${ }^{3}$
}

Abstract

In questo articolo si approfondisce il tema della radicalizzazione, in particolare quella femminile. In primo luogo, è definita la radicalizzazione; è fatta una distinzione fra i diversi tipi di radicalizzazione e si riflette su come venga innescata da fattori sociali e personali, con un focus sui fattori specifici di genere, attraverso una literature review. È inoltre illustrate la metodologia di ricerca adottata, che combina problematizzazione e pensiero progettuale. Questa metodologia ci permette di attingere alla conoscenza tacita degli agenti di cambiamento di base che sono a fondamento delle attività artistiche, nell'ottica di prevenire la radicalizzazione femminile. Essa facilita l'emersione e l'elaborazione di queste "invisibilità" in seno a e tramite le attività artistiche e le formazioni tenute nell'ambito del Progetto "CommUnity" (Horizon 2020, n. 871056). Nella riflessione critica finale, è evidenziata l'urgenza di lavorare su questi ruoli femminili radicalizzati sconosciuti, nella consapevolezza che siano queste invisibilità sociali a permettere il radicalismo.

Parole chiave: radicalizzazione femminile, Progetto "CommUnity", radicalismo, attività basate sulle arti, design thinking.

Abstract

In this paper, we problematise the concept of radicalisation, more in particular female radicalisation. First, we define radicalisation, differentiate between the types of radicalisation, and how it is enabled through both societal and personal factors and discuss gender-specific drivers through a literature review. Next, we discuss our methodology combining wicked problems and design thinking. This methodology allows us to tap into the tacit knowledge of the grass-root

${ }^{1}$ Senior Researcher - UC Leuven-Limburg (UCLL) Hogeschool, Research and Expertise, Belgium.

${ }^{2}$ Researcher - UC Leuven-Limburg (UCLL) Hogeschool, Research and Expertise, Belgium.

${ }^{3}$ Researcher - UC Leuven-Limburg (UCLL) Hogeschool, Research and Expertise, Belgium. 
change agents organising arts-based activities to prevent female radicalisation. It facilitates uncovering and working with blind spots within the arts-based activities and the training sessions held within the "CommUnity Project" (Horizon 2020, n. 871056). In our final critical reflection, we discuss the urgency of working with these unknown female radicalised roles as these societal blind spots enable radicalism.

Keywords: female radicalisation, "CommUnity” Project, radicalism, arts-based activities, design thinking.

\section{Introduction}

When thinking about the concept of radicalisation nowadays, a certain type of image pops up into our minds. We most probably relate it to males, violence - possibly armed figures -, and with a religious purpose. Media and specially media biases, such as the selection or deselection of stories based on ideological grounds and the coverage towards particular actors or issues play a big role in the way we understand and represent radicalisation (D'Alessio, Allen, 2000). Thus, nowadays, it is difficult to imagine someone other than a violent religious fanatic, when thinking of radicalisation.

However, is this an accurate view? In the "CommUnity" Project (Horizon 2020, n. 871056), we challenge this concept and question how we could prevent radicalisation through design thinking with arts-based activities. We start from a literature review defining radicalisation and its prevention, explain the methodological approach, the arts-based workshops and the training to open up the debate on female roles within radicalisation.

\section{Literature Review}

\subsection{Definitions of Radicalisation and Its Enablers}

During the glossary activity organised in the first training session of the "CommUnity" Project (Horizon 2020, n. 871056) (Huion, 2021), the need for a common understanding of radicalisation emerged. The term "radicalisation" is often used interchangeably with other terms like extremism, terrorism and nowadays often directly linked to religion. It is important to remark that radicalisation is not always and necessarily linked to violence. Preparing the first training sessions, we realised that radicalisation can also be positive. There are examples of radical movements, like pro earth organisations, whose sole purpose is a positive outcome. Nevertheless, in this article, we will focus and analyse the phenomenon of violent extremism, (the most radical expression), to develop tools to prevent radicalisation. In design thinking terms, the violent radicals are 'the extreme users'.

Radical ideas may have different motives and consequently, different outcomes depending on the root of the belief system. The sociologist Michael Kimmel (2018) states in his book Healing from hate - How Young Men Get Into-and Out of-Violent Extremism that it is not necessarily the ideals and ideology of the group that make someone join this group, but the need of belonging and being accepted and connected. Furthermore, for some people, the attraction of a radical group lies in their need for risk and adventure, including a fascination for violence and weapons (Doosje, van Eerten, 2017). 
For others, a radical group may provide answers in terms of their quest for meaning and significance (Kruglanski, Gelfand, et al., 2014). Other authors (Doosje, Loseman et al., 2013) mention uncertainty (personal or as a group) as a stimulator for radicalisation. The Organization for Security and Co-Operation in Europe (OSCE) has defined VERLT (violent extremism and radicalization that lead to terrorism) as «the dynamic process whereby an individual comes to accept terrorist violence as a possible, perhaps even legitimate, course of action. This may eventually, but not necessarily, lead this person to advocate, act in support of, or to engage in terrorism» (2014, p. 16).

According to the report Radicalisation Processes Leading to Acts of Terrorism, prepared by the EU's Expert Group on Violent Radicalisation, «radicalisation is a context-bound phenomenon par excellence. Global, sociological and political drivers matter as much as ideological and psychological ones» $(2008$, p. 7$)$. They mention multiple factors that could lead to radicalisation such as the international, national and regional milieu, the political situation within a country or city, the socio-economic circumstances and religious or ideological convictions and psychological state.

Note that although some factors can be considered as direct drivers of radicalisation, it is usually the convergence between several factors that favour the process of radicalisation. In the above-mentioned report, the authors identify three characteristics that political radicalisation waves resulting in terrorism from the late 19th century to the present day, have in common: an enabling environment characterized by a shared sense of injustice, marginalization, exclusion and humiliation, which constitutes as a powerful driver for change; an intersection of the enabling environment and the individual's personal trajectory, as not all individuals experiencing a sense of injustice will radicalize nor become violent. Radicalisation is highly dependent on personal factors such as socio-economic, psychological and social circumstances; finally yet importantly, the actual use of violence by radicalised people is very low, and only small groups resort to violence.

Actual violence is one of the least used expressions of radical ideas.

\subsection{Types of Radicalisation}

The Canadian Centre for the Prevention of Radicalization Leading to Violence (CPRLV), the first independent, non-governmental organisation aimed at preventing violent radicalization and providing support to individuals affected by the phenomenon, defines four types of radicalisation.

Right-wing radicalisation, which is associated with fascism, ultra-nationalism, racism and supremacism, is a form of radicalisation that is characterised by the violent defence of a racial, ethnic or pseudo-national identity, and is also associated with radical hostility towards state authorities, minorities, immigrants and/or left-wing political groups.

Politico-religious radicalisation is described as a form of radicalisation with a political interpretation of religion and the defence, legitimising violence, of a religious and/or ideological identity perceived to be under threat.

Left-wing radicalisation concentrates specifically on anti-capitalism, and advocates and seeks the transformation of political systems which are considered responsible for creating and maintaining social inequalities, and that might resort to violence in order to realize their cause.

Lastly, Single-issue extremism is motivated by one particular issue including, anti-gay groups, anti-abortion radicals, animal rights and radical environmental groups. 


\subsection{Types of Personal Motivators}

Added to the socio-economic enablers, there are personal variables that play a role in the feeling of discontent and frustration towards the system and the status quo, pushing them to the role of change agents for a better world. At a glance, it may seem that people who take a radical action share a common personal background and motivations, but there are numerous sources from where the desire for action can come from.

On one side, intrinsic, more introspective motivators, like grief caused by the death of a loved one or the own socio-political condition, seeking meaning in life and trying to belong, and on the other, extrinsic, more to the outside motivators, like the desire for action, seeking adventure and being heroic, often with the motivation of wanting to be exposed and seen by larger audiences, the general public or even media.

\subsection{Gender-based Approaches}

Gender as defined by The United Nations Office of the Special Advisor on Gender Issues and Advancement of Women refers to «the social attributes and opportunities associated with being male and female and the relationships between women and men and girls and boys, as well as the relations between women and those between men» $(2001$, p. 1$)$.

These attributes, opportunities and relationships are socially constructed and are learned through socialization processes. They are context/ time-specific and changeable. Gender determines what is expected, allowed and valued in a woman or in a man in a given context. In most societies, there are differences and inequalities between women and men in responsibilities assigned, activities undertaken, access to and control over resources, as well as decision-making opportunities. Gender is part of the broader socio-cultural context, which includes class, race, poverty level, ethnic group and age (United Nations Office of the Special Advisor on Gender Issues and Advancement of Women, 2001).

While there is no doubt that many men, women and children are forced or manipulated into joining VEOs (Violent Extremist Organisations), there is an urgent need to break the stereotyping of why individuals join such groups. Authorities as well as civil society need to recognize the agency of each individual who makes a conscious decision to join a VEO, including the gender differences in their motivations to do so.

Understanding these gender dimensions will allow for a better understanding of radicalization processes among both men and women, and for developing responses that are better suited to addressing the gender-based dynamics related to people choosing to join such groups (OSCE, 2019).

\subsubsection{Toxic Masculinity as Driver ${ }^{4}$}

As the majority of radicalised people are men, researchers have recently tried to understand the role of toxic masculinity as a driver for radicalisation to consider its role in the way of young men is transitioning into an extremist and radicalised person. OSCE defines toxic masculinity as «a notion referring to socially constructed attitudes that see, and celebrate, the stereotypical

\footnotetext{
${ }^{4}$ For further information, see Aycicek, Huion (2021) in this journal (from now on, unless otherwise noted, all footnotes are the Authors', Editor's Note).
} 
masculine gender role(s) as being violent, unemotional, sexually aggressive, dominant and so forth» $(2019$, p. 10).

Throughout the education of boys (depending on the culture) and male adolescence, men are confronted with phrases such as "man up", "don't be a girl", "the man of the house", "provide for the family", which restrict them from expressing and showing emotions openly, not allowing them to develop this ability. This contributes to the development of putting up and act behind a mask of the tolerated (toxic) definition of masculine, as understood in the wide society. The concept of "being a man" comes thus with attributes as tough, strong, never show weakness, win at all costs, suck it up, play through pain and so forth. When a young male is confronted with the "necessity" of being "masculine" under this definition and not being able to find the way to express his emotions in a family context, he will try to find a way to express and channel his emotions and frustration in some other way or context.

In their recruiting and propaganda, VEOs also take advantage of the notions of masculinity and femininity. In many traditional societies, "a good man" is often equated with being a strong family patriarch, defined in comparison to other men whom one seeks to surpass in status, wealth and social standing. Men who have difficulty meeting traditional expectations of masculinity — such as being the main income earner, being respected and honoured, or having access to sexual partners of choice - may find that VEOs offer a compelling substitute for confirming their masculinity (Ní Aoláin, 2018).

Jossif Ezekilov on his study about Gender Men-Streaming CVE: Countering ViolenceExtremism by Addressing Masculinities Issues, says that «the ubiquity of this strategy means that young men are drawn to violent extremist groups, less because of the groups' specific beliefs and more out of an inherent need to fulfil their identities as men» (2017, p. 1).

It is «the cultural ideal of manliness, where strength is everything while emotions are a weakness, where sex and brutality are yardsticks by which men are measured, while supposedly feminine traits - which can range from emotional vulnerability to simply not being hypersexual - are the means by which your status as man can be taken away» (O'Malley, 2016, n.d.). Therefore, toxic masculinity gathers much attention in terms of understanding radicalisation from a gender perspective.

\subsubsection{Female Radicals Fighting Personal Injustice: From Victims, Mothers, Wives and Sisters}

As described by Idris and Abdelaziz, the role of women in VEOs and terrorist groups has usually been seen as "passive, victims, helpless, subordinate and concerned family members" (2017, p. 2). Organisations that support women through programmes empowering and supporting them, sometimes do more harm than good by reinforcing stereotypes, for example by depicting women as helpless victims and overemphasising the role they can play as mothers (Haynie, Oudraat, 2017). This approach contributes to women being seen as "the ones who suffer": the ones that stay behind and grieve in the background, with no voice, no real role or say in the matter.

Suffering of gender-based inequality and discrimination, violence, lack of educational and economic opportunities and the consequent marginalisation and exclusion women have suffered, are variables that contribute and most probably will lead to feelings of injustice and humiliation. These factors create an enabling environment to want to fight personal injustice (El Feki, Heilman et al., 2017), that can lead to radicalisation. Being married to a terrorist and trying to protect their children and seeking liberty is also a factor that could contribute to women taking action. 
In the frame of the "CommUnity" Project, we want to analyse how the role of women is perceived and addressed in the arts-based activities that involve this target group.

\section{Methodology: Design Thinking Embracing Radicalisation as a Wicked Problem}

In the "CommUnity" Project (Horizon 2020, n. 871056), we question how to prevent radicalisation through design thinking with arts-based activities that include creative, musical, cinematographic and women and men centred activities organised by 11 organisations.

Through the literature review but also through the first training within the "CommUnity" consortium in 2019, we realised radicalisation and its prevention are defined in different ways and from different perspectives. For instance, in the third training participants from different backgrounds, thus different mental schemes, were divided in groups and asked to define together a series of concepts, like Gender, Identity and Radicalisation, which proved to be challenging. That is why we opted to approach radicalisation as a wicked problem which Rittel defines as «a class of social system problems which are ill-formulated, where the information is confusing, where there are many clients and decision makers with conflicting values and where the ramifications in the whole system are thoroughly confusing» (in Buchanan, 1992, n.d.).

A way to address wicked problems is through design thinking, a human-centred way of solving problems through creativity. The designer according to IDEO «dreams up wild ideas, takes time to tinker and test, is willing to fail early and often, he embraces empathy, optimism, iteration, creativity, and ambiguity. And most critically, design thinking keeps people at the centre of every process» (IDEO Design-thinking, n.d.). The designer is more like a modern-day Hercule Poirot: observing, asking questions, popping up at unexpected places with unfamiliar people, baffling links, asking people to play along in role-plays, mock-ups. And like this Belgian refugee of the first World War, the designer does not go for the obvious solution (quite often favoured by the police in Agatha Christie's novels) but asks questions, goes to people's homes, observes their responses, their body language, their emotions and finds the solution in links and contradictions nobody had even noticed.

The design thinking process consists of an iterative cycle of five steps: empathise, define, ideate, prototype, and test. In "CommUnity", we organise five cycles to define models to prevent radicalisation through community-building. Through monitoring reports of the arts-based activities, needs' analyses of consortium members organising the arts-based activities and training sessions we build up empathy with the grass-root change agents and their target audiences. In the define phase, the designer/consortium member has to formulate a point of view (POV) that is preferably a game-changer inspiring the designer/ consortium member to find new solutions.

We link this challenge to the first characteristic of wicked problems creating awareness that in defining the problem we are also defining the solution. The ideation is done at different meetings: between IDP and UCLL in Brussels and Diepenbeek, at the board meetings, during the conference in Florence and in bilateral meetings preparing the third localised training sessions. The training sessions and later the arts-based community building activities are testbeds for the prototypes.

\section{Case-studies: Arts-based "CommUnity” Activities Creating Hybrid Identities}

The "CommUnity" Project has chosen arts-based activities as a tool to create peaceful communities to contribute to the prevention of radicalisation because arts-based activities create a safe and entertaining atmosphere facilitating easy and less stressful ways of sharing ideas 
and self-expression (Peter, 2004). Hence, they promote more involvement of individuals into social activities with others and raise interactions among them. These activities also build new engagement bases among those who do not know each other while they also help strengthen the already existing bonds in more familiar groups. They also facilitate developing networks and foster trust-building among individuals through stimulating civic engagement in a safe atmosphere (Green, Haines, 2002). Additionally, they create the necessary atmosphere to express and tackle some problematic issues in a less threatening manner.

As such, arts-based community-building activities are the ideal platform to facilitate a design thinking trajectory creating peaceful communities in preventing radicalization.

In the following sections, we introduce the activities of our partners which consist of inspirational meetings with female writers (Fedactio, Belgium), music-inspired conversations (Forum Dialogue, Germany), conversations through intercultural activities (Islam Kennis Centrum, Netherlands) and employment coaching activities (Arco Forum, Spain) with a special emphasis on how these activities revealed the different roles of women in relation to radicalisation.

\subsection{Mothers and Prevention Agents in Fedactio's Inspirational Debates with Female Writers}

Fedactio organises a series of inspirational meetings in the form of debates with female writers including a female moderator. The speakers are Saliha Ben Ali ${ }^{5}$, Dominique Thewissen ${ }^{6}$ and Malika Hamidi ${ }^{7}$. These speakers are not merely care-giving mothers, serving psychotherapists or sociologists; but they are highly educated activists who initiate action in the public sphere to tackle some problematic issues including prevention of radicalisation.

This is also manifested in the debates. In the debates, the question "how mothers/women can take more action to tackle radicalisation not only in the family but also in their community» is addressed. For example, Ms. Thewissen underlined that there is a close relation between development of self-esteem and risk of being radicalised for young people and introduced the ways in which mothers could help their children to develop their self-esteem in a healthy way. This topic gained much attention from the participants and they asked for further meetings

${ }^{5}$ Ben Ali is a mother whose son joined ISIS, left his home and died in Syria in 2013. Since then, as a victim of the ISIS and a mother of a jihadist, she has decided to take action to prevent other innocents from being radicalized. She founded the "SAVE Belgium" (Society Against Violent Extremism Belgium) in order to take action publicly and permanently. She is also a member of "Mothers for Life". She initiates several discussion groups with other parents and with youngsters in schools and youth associations to share her experiences and raise awareness to prevent youth radicalization. She bundled her experiences in a book titled Maman, entends-tu le vent? (Mom, can you hear the wind?) (Mothers for Life, 2021).

${ }^{6}$ Dominique Thewissen is a psychotherapist specialized in the systems approach and family therapy. She is also a lecturer who is regularly invited to conferences and debates. Converted to Islam, being a feminist and an experienced psychotherapist, she has a critical approach to the religious texts and fights against patriarchy and inequality. She wrote a book called Psy, convertie à l'islam et féministe (Psychotherapist, converted to Islam and feminist) (France Culture, 2021).

${ }^{7}$ Malika Hamidi is a sociologist focusing on Muslim presence and Muslim feminists in Europe aiming to explore their identity strategies and methods of mobilization. She has several publications such as Muslim feminism, and why not? and Islamic Feminism (CADIS, 2019). She has been regularly invited to intervene on issues related to radicalisation in recent years. Her point of view, as an academician and as an activist in Europe and in Muslim communities, allows her to propose original answers to the complex questions of radicalisation, feminism, and Islam. She is also experienced in working in the field with mothers in the mosques advocating an Islam of peace and equality. (EHESS, 2021). 
and events that they would be able to follow. This shows how women and mothers are eager to take up their role as a preventive-agent.

It was also the case in the debate with Ms. Ben Ali who set an example of an active mother also in the public sphere to prevent radicalisation. Most participants asked her for the other events that Ben Ali would undertake to follow her works and began to follow her through social media.

Feminism and Islam and different perspectives of reading religious texts in terms of patriarchy and equality were also among the topics handled in the debates, especially in the once with Malika Hamidi. These debates were interesting in the sense that these issues are/were taboo for most participants. For example, one participant advocated that feminist ideology does not suit the religious teachings of Islam. However, Malika Hamidi explained her position very politely by stating that there can be different perspectives and positionings considering religion and she finds feminism can be linked with Islamic values. After the meeting, the same participant got in touch with the moderator. She said that, after a clear thinking about what Hamidi said, she felt Hamidi had introduced a different perspective and feminism is no longer a threat for her. She began to see it as a different positioning. Besides that, some participants indicated that they were approaching feminism as a threat before the debate, but after having attended to this event, they realised that they were already feminist in the sense that they defend equal rights for all.

Most of the participants reflected after the meetings that inspirational meetings have broadened their perspectives. They were eye-openers. Additionally, seeing clear and concrete examples of active women tackling radicalisation also in the public sphere has made them excited.

\subsection{Vulnerable, Newly Arrived Young Female Refugees and Supporting-peers in Forum Dialogue's Music-inspired Conversations}

Forum Dialogue organises music lessons for newly arrived young female refugees since they are particularly vulnerable due to their experiences of displacement, the new circumstances in the host country and the search for their places in this new society. These classes are held by a teacher and a moderator.

They all play music with different instruments such as guitar, accordion, cello and get relevant solfege training. Two participants are the vocalists. So far, they have separately studied songs, but the aim is to perform the same songs in a concert in July.

At the beginning, the participants were reluctant. For example, they were shy even while introducing themselves to the group and not much conversation was taking place among them. Still, there were some factors facilitating their attendance. For example, the music teacher comes from the same background, a Muslim refugee. The moderator is an established migrant coming from the same background as well. The moderator is learning to play an instrument with these youngsters allowing them to relate with her straightforwardly. This made her a part of the team fostering a relation of trust between her and the participants. These factors made participation for the girls easier, together with their eagerness to learn to play an instrument.

With the art of music and the atmosphere it creates, participants have become more comfortable in the following lessons and they began to ask for help also from each other, not only from the teacher or the moderator. They seem to be more relaxed and engaged, and they are communicating with each other more and sharing their daily life experiences.

In the course of time, it is observed that these young female refugees have become a supporting peer-group. They are not only asking for help from each other in terms of playing their instruments but also about their daily struggles. For example, one of them was having trouble 
learning a grammar rule of the host country language and shared it, and others helped her in this issue. They have also created a Whatsapp group, in order to share their questions regarding their other lessons and to improve their language skills. When they discover something new in the host country such as a new place to visit, a new taste or something else, they immediately share it in the group. The moderator has stated that they have grown from vulnerable individuals into a dynamic and supportive group.

While they practice, study and absorb music, they also develop their self-esteem. They do not act hesitantly anymore towards each other. They ask their questions directly to the teacher. They also ask for help from the moderator concerning their other issues, for instance, how to apply to a sports club and where to find second-hand books. Moreover, they shared in the lessons that being able to play a music instrument facilitates their interactions with other friends from the host country. One participant reflected that she felt she had something valuable to share and it facilitated her communication in the school, as music is a universal language.

\subsection{Mothers and Dialogue-Creators in Islam Kennis Centrum's Intercultural Conversations}

Islam Kennis Centrum (IKC) organizes conversations, debates and intercultural activities with women and mothers. They try to reach the re-organisation of $I$-positions, restoration of a sense of belonging, and an increase in awareness of human values through broadening the understanding of the other and improving the art of dialogue. IKC believes this will promote participation of Muslim women in Dutch society through helping them to express their identity and beliefs in a peaceful and democratic manner.

In this sense, IKC focused on how they could promote Muslim women's participation in Dutch society. Around this question, they discovered the most challenging topics fostering tension between Muslim communities and other communities in The Netherlands: "homosexuality and Islam" and "the position of Muslims in Christmas celebrations". They organised debates on these issues. The participants were mostly reluctant against the issues being handled, especially against homosexuality. Nevertheless, some participants expressed that they knew it is a right of a person but still they do not wish their children to make the same choice. Most of them indicated that they do not see any difference between homosexuals and themselves as having the same rights and responsibilities, but they might need more orientation on how to contact and get in touch with those people since these people might also have some prejudices against Muslims/ Muslim women.

Regarding Christmas celebration, they seemed relatively more interested and relaxed about this topic. They stated that especially their little children would like to celebrate Christmas, also at home. In the debates, it is addressed that Christmas celebrations could be a way of engaging with the larger society and with the neighbours belonging to a different culture. It came up during the debate that sending Christmas greetings to their neighbours would be a good idea to reflect their good intentions and to foster dialogue in the society.

The participants of the IKC reflected about their feelings after the debates either through face-to-face conversations with the organizers or through filling in questionnaires. They stated after the debates that they began to feel more comfortable about these topics. As they were among the "taboo topics" in their communities, exploring such issues also through an organization dealing with Islamic knowledge, have been an eye-opener event for most of them.

Although tackling such issues are challenging, introducing them and letting Muslim women relate with these issues by an Islamic organisation can be seen as a success in itself. Moreover, most participants' reflections as sending greetings to their Christian neighbours and 
seeing homosexuality as a personal choice are crucial in creating dialogue between Muslim communities and Dutch society. They also reveal that women can also play other roles such as dialogue-creators between different cultures.

\subsection{Mothers and Employees in ARCO Forum's Employment Coaching Activities}

ARCO Forum organises (online) dynamic meetings in the form of conversations, avoiding monotonous speeches and fostering dynamic experience-sharing as much as possible. These meetings mainly target established and new-comer (Muslim) women and mothers. The main topics of the meetings are women's leadership, women at work and in the labour market. Each event includes a moderator playing a "friend-role", to show that they understand the participants' concerns and their daily struggles.

ARCO Forum selects its speakers from those who have a migrant Muslim background and who managed to take part in the Spanish labour market. Doing so, they aim to establish a role model for their participants, also to create a network for them in their path of finding a job and integrating into society as a whole. They offer, in this sense, employment coaching as an empowerment strategy for their participants.

Their approach apparently introduces another role that women can play: women as employees. They believe that, promoting women's, especially migrant women's, participation into the labour market will eventually lead to positive contributions to the prevention of radicalization as they will feel more included and welcomed in the host country and they will transmit this mind-set to their family and community.

\subsection{Critical Reflection: From Mothers, Newly Arrived Refugees to Allies Preventing Radicalisa- tion}

We see a similar pattern in all arts-based community-building activities. They start from the known identities of "passive, victims, helpless, subordinate and concerned family members" and link them to peers who take up an active role in the public realm. They counter gender inequality with role-models of highly educated speakers and moderators from their community. They facilitate building communities of practice where they can share their questions and expertise. They empower them through employment trajectories. They are motivated to become bridging figures between their communities and the communities of the host countries.

Overall, the arts-based community building activities prevent radicalisation through inclusion, education, economic opportunities and promoting women as activists countering radicalisation both at home as well as in society. Yet, there is one more step to go.

\section{From Allies...}

In October 2020, "CommUnity" organised a second staff training in which the test activity, "CampiagnIA", was introduced. In the CampaignIA workshop we invited the staff members to prepare a campaign based on the roles of women preventing radicalisation as discovered in their workshops. However, we also asked them to build a campaign on 'preventing female radicalisation'.

We observed that the group dealing with 'women's role in preventing radicalisation' quickly figured it out and reinstalled women as mothers and they identified their roles as the protection of their children and families from being radicalised. 
The other group being given 'preventing female radicalisation' as their campaign subject firstly and directly approached it as "how women can prevent radicalisation", and some group members said mothers could play a role in preventing radicalisation. It was not until after the discussions initiated by the moderator, that they began to consider women as radicals.

\section{1. ... to Radicalised Women}

The evaluations of the activities in the "CommUnity" Project and the above-mentioned reflection from the staff training reveal that, there is a blind spot regarding 'women and radicalisation'.

We usually do not imagine women as being a radical. It creates a kind of uncomfortable feeling within ourselves. Nevertheless, according to the European Parliamentary Research Service (EPRS, 2018) 17\% of European fighters are women. Moreover, according to Europol (as cited in EPRS, 2018), one in four people arrested in the EU for terrorist activities in 2016 was a woman. They state that women have not only been active in auxiliary and support capacities, but also as leaders in organisation, recruitment and fund-raising and in direct operational roles. They also argue that «the increasing use of the internet is levelling the playing field for women to join radical organisations that are now accessible virtually and anonymously» (EPRS, 2018, p. 2).

We must recognize that women can be suicide bombers, active fighters, leaders, propagandists, recruiters, and fundraisers of radical groups (Banks, 2019; EPRS, 2018). And it is also evident that, these examples are valid in terms of all types of radicalisation that can go from co-founder of a pro-socialist organization in Germany using violence as a tool, or a Russian female terrorist who tries to assassinate the governor in Petersburg, to suicide bombers affiliated to Hezbollah, the Tamil Tigers, Hamas and recently affiliated to ISIS (Banks, 2019).

\subsection{And from Radicalised Women... to Community Builders}

Being aware of the fact that radicalised females exist, allows us to analyse for example, the circumstances in which women are being recruited. Terrorist groups, have started recruiting women, knowing, that a female terrorist draws less attention to the security services, media and the general public, compared to a male, due to gender biases that attribute violence mainly to men (Mahmood, 2019).

In addition, violent groups prefer to recruit women in order to attract more publicity, since an attack undertaken by a female terrorist is likely to generate more attention and a shocking effect (Bloom, 2011; Richardson, 2007; Speckhard, 2008). Recruiting women, is also used by terrorist organizations as a way of man-shaming, to increase men's involvement (Mahmood, 2019), exploding the existing previously discussed toxic masculinity.

\section{Reflection}

A gender-based perspective is much needed in policies and approaches to prevent radicalisation. Both genders suffer from biased views in the problem definition preventing radicalisation. Indeed, ignoring toxic masculinity in prevention strategies renders prevention measures as inefficient as sticking to female roles of passive, home-bound victims. Ignoring women as active radicals creates ample opportunities for radical organisations. Moreover, even though, the "CommUnity" consortium members prototyped roles of women as allies of prevention strategies, 
becoming employees, public activists, dialogue-builders, supporting friends, informed mothers as change agents, they all reverted to the more familiar passive, female roles in the test phase.

Therefore, we reformulate the "CommUnity"'s problem definition: how can we hold the space for the stories of all women - passive, allies, radicalised - attached to right-wing or leftwing radical groups, to single-issue or politico-religious groups, to acknowledge their personal and societal grievances thus harnessing their capacities as prevention agents? Would this not be game-changing?

\section{References}

Aycicek H., Huion P. (2021): Not All Migrant Men Embrace Toxic Masculinity, Do They? (Manuscript in preparation).

Banks C. (2019): Introduction: Women, Gender, and Terrorism: Gendering Terrorism. Women \& Criminal Justice, 29(4-5), pp. 181-187.

Bloom M. (2011): Bombshell: Women and Terrorism. Philadelphia: University of Pennsylvania Press.

Buchanan R. (1992): Wicked Problems in Design Thinking. Design Issues, 8(2). Cambridge (MA): The MIT Press (http://www.jstor.org/stable/1511637; last access: 02.02.21).

Centre d'Analyse et D'Intervention Sociologiques (CADIS) (2019): Malika Hamidi (http://cadis.ehess. fr/index.php?1250; last access: 05.01.21).

D’Alessio D., Allen M. (2000): Media Bias in Presidential Elections: A Meta-Analysis. Journal of Communication, 50(4), pp. 133-156.

Doosje B., Loseman A., van den Bos K. (2013): Radicalisation Process of Islamic Youth in the Netherlands: The Role of Uncertainty, Perceived Injustice and Perceived Group Threat. Journal of Social Issues, n. 69, pp. 586-604.

Doosje B., van Eerten, J. (2017): De-Radicalisation Scientific Insights for Policy. Brussels: Flemish Peace Institute (https://vlaamsvredesinstituut.eu/wp-content/uploads/2017/07/deradicalisering_eng_ lowres.pdf; date last access: 02.02.21).

EHESS (2021): Academicians: Malika Hamidi (https://ehess.academia.edu/MalikaHamidi; last accesse: 02.01.21).

El Feki S., Heilman B., Barker G. (2017): Understanding Masculinities: Results from the International Men and Gender Equality Survey (IMAGES) - Middle East and North Africa. Cairo and Washington D.C.: UN Women and Promundo-US.

European Union's Expert Group on Violent Radicalisation. (2008): The Report Radicalisation Processes Leading to Acts of Terrorism (https://biblio.ugent.be/publication/446365/file/6814706; last access: 03.02.21).

European Parliamentary Research Service (EPRS): (2018). Radicalisation and Counter Radicalisation: A Gender Perspective. Members' Research Service (https://www.europarl.europa.eu/EPRS/EPRSBriefing-581955-Radicalisation-gender-perspective-rev-FINAL.pdf; last access: 05.05.20).

Ezekilov J. (2017): Gender "Men-Streaming" CVE: Countering Violence Extremism by Addressing Masculinities Issues. George Washington University. (https://pubs.lib.umn.edu/index.php/ reconsidering/article/view/908/978; last access: 01.01.21).

France Culture (2021) : Personne: Dominique Thewissen (https://www.franceculture.fr/personne/ dominique-thewissen\#biography, date last accessed: 03.01.21).

Green G.P., Haines A. (2002): Asset Building and Community Development. Thousand Oaks (CA): Sage.

O’Malley H. (2016): The Difference between Toxic Masculinity and Being a Man (https://goodmenproject. $\mathrm{com} /$ featured-content/the-difference-between-toxic-masculinity-and-being-a-man-dg/; last access: 02.02.21).

Haynie J., Oudraat C. (2017): Women, Gender and Terrorism: Policies and Programming. Women in International Security - Policy Brief. London: GSDRC (https://wiisglobal.org/wp-content/ uploads/2014/02/Women-Gender-and-Terrorism-Policies-and-Programming.pdf, date last accessed: 25.12.20). 
Huion P. (ed.) (2021): Training Programme-The CommUnity Project. Leuven: University Catholic Leuven Limburg Hogeschool, Research and Expertise (Manuscript in preparation).

IDEO (n.d.): Design Thinking Defined. Designer's Mindset (https://designthinking.ideo.com/\#designersmindset; last access: 02.01.21).

Idris I., Abdelaziz A. (2017): Women and Countering Violent Extremism. Helpdesk Research Report. London: GSDRC (May 2017; https:/gsdrc.org/wp-content/uploads/2017/05/HDR_1408.pdf; last access: 24.12.20).

Kimmel M., Wade L. (2018): Ask a Feminist: Michael Kimmel and Lisa Wade discuss the role of toxic masculinity. University of Chicago (http://signsjournal.org/kimmel-wade-toxic-masculinity/, date last accessed: 01.01.21).

Kimmel M.S. (2018): Healing from Hate: How Young Men Get Into-and-Out of Violent Extremism. Berkeley (CA): University of California Press.

Kruglanski A.W., Gelfand M.J., Bélanger J.J., Sheveland A., Hetiarachchi M., Gunaratna R. (2014): The Psychology of Radicalization and Deradicalization: How Significance Quest Impacts Violent Extremism. Political Psychology, n. 35, pp. 69-93 (http://www.jstor.org/stable/43783789; last access: 24.12.20).

Mahmood S. (2019): Negating Stereotypes: Women, Gender, and Terrorism in Indonesia and Pakistan. Perspectives on The Future of Women, Gender and Violent Extremism, pp. 11-20 (https://extremism. gwu.edu/sites/g/files/zaxdzs2191/f/Negating\%20Stereotypes-\%20Women\%20Gender\%20and\%20 Terrorism\%20in\%20Indonesia\%20and\%20Pakistan.pdf; last access: 03.02.21).

Mothers for Life (2021): Saliha Ben Ali (http://www.mothersforlife.org/en/keyparents/saliha-ben-ali; last access: 19.01.21).

Ní Aoláin F. (2018): Masculinity, Jihad and Mobilization. New York: Just Security (https://www. justsecurity. org/33624/masculinity-jihad-mobilization; last access: 01.02.21).

OSCE (2014): Preventing Terrorism and Countering Violent Extremism and Radicalization that Lead to Terrorism: A Community-Policing Approach (https://www.osce.org/secretariat/111438?download= true; last access: 01.01.21).

OSCE (2019): Understanding the Role of Gender in Preventing and Countering Violent Extremism and Radicalization That Lead to Terrorism. Good practices for Law Enforcement (https://www.osce.org/ secretariat/420563; last access: 02.01.21).

Peter S. (2004): The Art of Building Community: The Role of the Arts in Community Development (https:// pol.illinoisstate.edu/downloads/conferences/2004/Sally_Peters_aced.pdf; last access: 19.01.20).

Richardson L. (2007): What Terrorists Want: Understanding the Enemy and Containing the Threat. New York: Random House Trade.

Speckhard A. (2008): The Emergence of Female Suicide Terrorists. Studies in Conflict \& Terrorism. Routledge, 31(11), pp. 995-1023.

United Nations Office of the Special Advisor on Gender Issues and Advancement of Women (2001): Gender Mainstreaming: Strategy for Promoting Gender Equality (https://www.un.org/womenwatch/ osagi/pdf/factsheet1.pdf; last access: 01.01.21). 
